\title{
Exploration of $\alpha 1$-Antitrypsin Treatment Protocol for Islet Transplantation: Dosing Plan and Route of Administration
}

\author{
Boris M. Baranovski, Eyal Ozeri, Galit Shahaf, David E. Ochayon, Ronen Schuster, \\ Nofar Bahar, Noa Kalay, Pablo Cal, Mark I. Mizrahi, Omer Nisim, Pnina Strauss, \\ Eran Schenker, and Eli C. Lewis
}

Department of Clinical Biochemistry \& Pharmacology, Faculty of Health Sciences, Ben-Gurion University of the Negev, BeerSheva, Israel, Kamada, LTD., Israel; Department of Clinical Biochemistry \& Pharmacology, Faculty of Health Sciences, BenGurion University of the Negev, Beer-Sheva, Israel (B.M.B, E.O., G.S., D.E.O., R.S., N.B., N.K., P.C., M.I.M., O.N., E.C.L.); and Kamada, LTD., Israel (P.S., E.S.)

Received June 25, 2016; accepted September 15, 2016

\begin{abstract}
Lifelong weekly infusions of human $\alpha 1$-antitrypsin (hAAT) are currently administered as augmentation therapy for patients with genetic AAT deficiency (AATD). Several recent clinical trials attempt to extend hAAT therapy to conditions outside AATD, including type 1 diabetes. Because the endpoint for AATD is primarily the reduction of risk for pulmonary emphysema, the present study explores hAAT dose protocols and routes of administration in attempt to optimize hAAT therapy for isletrelated injury. Islet-grafted mice were treated with hAAT (Glassia; intraperitoneally or subcutaneously) under an array of clinically relevant dosing plans. Serum hAAT and immunocyte cell membrane association were examined, as well as parameters of islet survival. Results indicate that dividing the commonly prescribed $60 \mathrm{mg} / \mathrm{kg}$ i.p. dose to three $20 \mathrm{mg} / \mathrm{kg}$ injections is
\end{abstract}

superior in affording islet graft survival; in addition, a short dynamic descending dose protocol $(240 \rightarrow 120 \rightarrow 60 \rightarrow 60 \mathrm{mg} / \mathrm{kg}$ i.p.) is comparable in outcomes to indefinite $60 \mathrm{mg} / \mathrm{kg}$ injections. Although pharmacokinetics after intraperitoneal administration in mice resembles exogenous hAAT treatment in humans, subcutaneous administration better imitated the physiologic progressive rise of hAAT during acute phase responses; nonetheless, only the $60 \mathrm{mg} / \mathrm{kg}$ dose depicted an advantage using the subcutaneous route. Taken together, this study provides a platform for extrapolating an isletrelevant clinical protocol from animal models that use hAAT to protect islets. In addition, the study places emphasis on outcome-oriented analyses of drug efficacy, particularly important when considering that hAAT is presently at an era of drug-repurposing toward an extended list of clinical indications outside genetic AATD.

\section{Introduction}

$\alpha 1$-Antitrypsin (AAT) is an acute phase protein administered as an augmentation therapy for patients with genetic AAT deficiency (AATD). However, preclinical data suggest that AAT treatment may benefit conditions outside AATD, including transplant rejection, as well as ischemia-reperfusion injury, collagen-induced arthritis, graft-versus-host disease, experimental autoimmune encephalomyelitis, lupus, and preeclampsia (Daemen et al., 2000; Lewis et al., 2005; Lewis et al., 2008a; Grimstein et al., 2010; Subramanian et al., 2011; Tawara et al., 2012; Gao et al., 2014; Feng et al., 2015; Elshikha et al., 2016; Feng et al., 2016). AAT displays particular benefit in the case of inflamed pancreatic islets both in vitro and in vivo, as reviewed in Fleixo-Lima et al. (2014).

Several clinical trials presently address the potential benefit of AAT therapy to individuals without AATD, including islet and lung transplantation, type 1 diabetes (T1D), graft-versus-

This study was supported by the Juvenile Diabetes Research Foundation (JDRF) and Israel Science Foundation (ISF)-JDRF Joint Program in Type 1 Diabetes Research.

dx.doi.org/10.1124/jpet.116.236067. host disease, acute myocardial infarction, and cystic fibrosis (Lior et al., 2016). In the case of T1D clinical trials, the initial dosing plan for assessing islet protection by AAT was directly borrowed from the long-standing protocols of AAT augmentation therapy for AATD patients, e.g., weekly infusions of $60-80 \mathrm{mg} / \mathrm{kg}$ plasma-derived affinity-purified human AAT (Balbi et al., 2016). Limited by these constraints, it is a rather unexpected that clinical trials that introduced serial AAT infusions to patients with recent onset T1D presented data suggestive of a possible positive change in disease course. Specifically, in a 12-participant trial (ages 12-39 years old), the duration of treatment consisted of 8 consecutive weekly infusion sessions (Gottlieb et al., 2014), and $80 \mathrm{mg} / \mathrm{kg}$ AAT; an 18-month follow up established improved circulating c-peptide levels in 5 of the patients. Consistent with these findings, a 24-participant trial (ages 9-17 years old) tested a total of 18 infusions in a decreasing frequency of infusion sessions: 12 consecutive weekly infusion sessions of AAT, then four infusions 2 weeks apart, followed by two infusions 4 weeks apart (Wewers et al., 1987). The dose of AAT was 40, 60, and $80 \mathrm{mg} / \mathrm{kg}$ in three randomized groups; according to the 37-week long follow up, improvement in individual HbA1c levels was

ABBREVIATIONS: AAT, $\alpha 1$-antitrypsin; AATD, AAT deficiency; BMDC, bone marrow-derived dendritic cell; CT, control; DAMP, danger-associated molecular pattern molecule; IFN, interferon; IL, interleukin; STZ, streptozotocin; ThG, thioglycolate; T1D, Type 1 diabetes. 
established in all participants. Eight patients displayed a $2.94 \pm 1.55 \%$ decline in $\mathrm{HbA} 1 \mathrm{c}$ (compared with a $0.95 \pm 1.83 \%$ decline in $\mathrm{HbA} 1 \mathrm{c}$ in the remainder of the cohort) independent of dose. Both studies displayed remarkable safety and compliance at $\leq 80 \mathrm{mg} / \mathrm{kg}$. However, not being placebo-controlled, diabetesrelated outcomes must be interpreted accordingly.

More recent clinical trials were designed to evaluate the safety and efficacy of several doses of AAT for T1D, including 120 and $180 \mathrm{mg} / \mathrm{kg}$ (NCT02005848 and NCT02093221, respectively); in parallel, the $120 \mathrm{mg} / \mathrm{kg}$ dose is evaluated as replacement therapy for AATD patients (Sorrells et al., 2015). Although treatment of AATD patients is lifelong, and its success is based solely on decreased prevalence of emphysema (Balbi et al., 2016), the timing and duration of the treatment course required for pancreatic islet preservation has no precedent that may help in extrapolating a relevant treatment protocol. Also, unlike T1D, lung emphysema is not an immune disorder, rendering the course of AAT treatment of both these conditions distinct. Ideally, an islet-protective protocol would be tailored in a mechanism-oriented and function-specific manner, aiming at an endpoint that incorporates islet viability and function.

During a physiologic acute phase response, circulating AAT levels rise 4- to 6-fold for the duration of about 2 weeks, depending on the severity of the underlying inflammatory trigger; the levels gradually decline, coincide with its 3- to 4-day half-life in human plasma. It was reported that hAAT binds to cell surface to execute its activity (Subramaniyam et al., 2010). In contrast, the kinetics of exogenous AAT in humans is comprised of a narrow 24-hour-long spike-like surge that is followed by a sharp decline and subsequent plateau; it has yet to be determined where the molecule is sequestered upon decline under these conditions. Unlike exogenous delivery, continuous release of AAT into the circulation, as achieved by gene delivery of a human AAT-expressing plasmid to mice, despite markedly lower levels of circulating AAT compared with those attained by infusion-based approaches, results in protection of islets (Shahaf et al., 2011). In this regard, it is possible that a distinct distribution of infused AAT might represent an important parameter for diabetes-related trials.

In the present study, we explore several parameters of AAT treatment protocol in an islet allograft transplantation model. In this model, we address the initial days of engraftment ( $\leq 14$ days) as representing rapid inflammation-related compromised islet survival and function. In contrast, we consider the subsequent advanced weeks to represent the immune response toward the graft. Because this is the first study to directly examine a nonlyophilized preparation of human AAT for islet protection (Glassia, Kamada Ltd., Ness-Ziona, Israel), we also provide an in vitro exploration of its protective effects on primary islets.

\section{Materials and Methods}

Animals. Seven-week-old transgenic hAAT-heterozygote female mice, background strain C57BL/6, a kind gift from Prof. Churg A, University of British Columbia, Vancouver, Canada (Dhami et al., 1999), were used as graft recipients as described (Ashkenazi et al., 2013). Circulating levels of hAAT in these mice are below detection, as determined by specific ELISA for human AAT (sensitivity $10 \mathrm{ng} / \mathrm{ml}$ in serum, Immunologic Consultants Laboratory, Inc., Portland, OR). Pancreatic islets and dendritic cells were isolated from 7- to 8-weekold wild-type female CBA/2 mice (Jackson Laboratories, Bar Harbor $\mathrm{ME}$ ). Experiments were approved by the Ben-Gurion University of the Negev Animal Care and Use Committee.
Pancreatic Islet Culture Experiments. Pancreatic islets were isolated as described elsewhere (Lewis et al., 2008b). Briefly, donor mice were anesthetized, and pancreata were inflated with collagenase ( $1 \mathrm{mg} / \mathrm{ml}$, type XI, Sigma-Aldrich, Rehovot, Israel), excised, and incubated for 28 minutes at $37^{\circ} \mathrm{C}$. Digested pancreata were vortexed and filtered through a $500-\mu \mathrm{m}$ sieve and the pellet was washed in Hanks' balanced salt solution containing $0.5 \%$ bovine serum albumin (Sigma-Aldrich). The pellet was resuspended in RPMI 1640 medium supplemented with $10 \%$ fetal calf serum, $50 \mathrm{U} / \mathrm{ml}$ penicillin, and $50 \mu \mathrm{g} / \mathrm{ml}$ streptomycin, all from Biologic industries, Beit-Haemek, Israel. Islets were collected on a $100-\mu \mathrm{m}$ cell strainer (BD Biosciences, Bedford, MA) and hand-picked under a stereomicroscope. For in vitro studies, 35 islets per well in triplicates were stimulated with $5 \mathrm{ng} / \mathrm{ml}$ recombinant murine interferon (IFN)- $\gamma$ and $5 \mathrm{ng} / \mathrm{ml}$ recombinant murine IL-1 $\beta$ (R\&D Systems, Minneapolis, MN) in the absence or presence of $0.5 \mathrm{mg} / \mathrm{ml}$ human AAT (Glassia, Kamada Ltd., Ness-Ziona, Israel). Forty-eight hours later, supernatants were collected for analysis by Q-Plex mouse cytokines chemiluminescence-based 8-p ELISA (Quansys Biosciences, Logan, UT). Each cytokine was quantified by densitometry using Quansys Q-View software (Quansys Biosciences). Supernatant nitric oxide levels were evaluated by nitrite measurement using Griess reagent (Promega, Madison, WI). Islet viability was determined by XTT assay, according to manufacturer's instructions (Sigma-Aldrich).

Islet Allograft Transplantation. Recipient mice were rendered hyperglycemic by single dose streptozotocin (STZ, $225 \mathrm{mg} / \mathrm{kg}$ i.p., Sigma-Aldrich), and 450 islets were grafted under the renal capsule, as described (Lewis et al., 2008b). Briefly, recipient mice were anesthetized and an abdominal-wall incision was made over the left kidney. Isolated islets were then released into the renal subcapsular space through a puncture in the capsule, which was rapidly sealed with $1-\mathrm{mm}^{3}$ sterile absorbable gelatin sponge (Surgifoam, Ethicon, Somerville, NJ). Blood glucose levels were determined three times a week from tail blood by a standard glucometer (Roche Pharmaceuticals, Hod Hasharon, Israel).

Generation of Bone Marrow-Derived Dendritic Cells. Dendritic cells were generated from bone marrow progenitors, as described elsewhere (Lewis et al., 2008b). Briefly, bone marrow was prepared from femurs and tibias of donor mice. Cells were seeded at $3 \times 10^{3}$ cells per culture plate, in $10 \mathrm{ml}$ RPMI 1640 medium supplemented with $10 \%$ fetal calf serum, $2 \mathrm{mM} \mathrm{L}$-glutamine, $50 \mathrm{U} / \mathrm{ml}$ penicillin and $50 \mu \mathrm{g} / \mathrm{ml}$ streptomycin. Medium was added $10 \mathrm{ng} / \mathrm{ml}$ recombinant granulocyte macrophage colony stimulating factor (GM-CSF, Prospec, Rehovot, Israel). After 8 days, BMDC entered in vitro assays.

DC Maturation Assays. Bone marrow-derived dendritic cells (BMDC) were stimulated with IFN $\gamma$ and IL-1 $\beta$ ( $5 \mathrm{ng} / \mathrm{ml}$ each, Prospec), in the absence or presence of human AAT $(0.5 \mathrm{mg} / \mathrm{ml})$. Forty-eight hours later, supernatants were collected for cytokine and nitrite analysis. In the same manner, 24 hours after stimulation, cells were examined by flow cytometry, as described (Lewis et al., 2008b). The following antibodies were used for staining: anti-CD86-FITC, anti-MHC class II-PE and antiCD11c-APC (all from eBioscience, San Diego, CA).

hAAT Treatment Protocol. All in vivo hAAT treatments begun 1 day before islet transplantation and were repeated every 3 days, based on previously reported islet transplantation experiments (Lewis et al., 2005; Lewis et al., 2008a; Ashkenazi et al., 2013), unless otherwise specified. The route of administration included either intraperitoneally or subcutaneously, as indicated, and the doses included $15,20,30,60,120$, and $240 \mathrm{mg} / \mathrm{kg}$, as specified in each experimental group.

hAAT Distribution Study. Serum from nongrafted hAATtreated mice was collected using a designated microvette (Fisher Scientific, Waltham, MA). Circulating hAAT levels were detected using species-specific ELISA for human AAT (Immunologic Consultants Laboratory, Inc.). Membrane-associated hAAT was determined by flow cytometry of thioglycolate-elicited peritoneal cell lavages using anti-hAAT-FITC (Bethyl Laboratories, Inc., Montgomery, TX) and 
anti-CD45-PE (eBioscience) antibodies. Peritoneal macrophages were pulsed with Glassia for indicated time points and lyzed, and hAAT content was depicted by Western blot analysis using goat anti-human AAT (Bethyl Laboratories, Inc.) and mouse anti- $\beta$-actin (MP Biomedicals, Santa Ana, CA) antibodies.

Histology. Islet graft-baring kidneys were removed 7 days after graft failure or $>90$ days after normoglycemia and preserved in $10 \%$ formalin (Sigma-Aldrich) for 24 hours and then transferred into 70\% ethanol for another 3 days. Samples were embedded in paraffin and then cut into $5-\mu \mathrm{m}$ sections. Histologic sections were stained by hematoxylin and eosin (H\&E, Dako, Carpinteria, CA).

Statistics. Two-way ANOVA or Student's $t$ test was used to assess differences between groups. $P<0.05$ was considered statistically significant. Results are presented as mean \pm S.E.M.

\section{Results}

Glassia Improves Primary Islet Function, Decreases the Degree of Inflammation, and Reduces Dendritic Cell Maturation. To assess the function of inflamed islets in the presence of Glassia, primary mouse islets were stimulated with interleukin (IL)- $1 \beta$ and interferon $\gamma$ (IFN $\gamma ; 5 \mathrm{ng} / \mathrm{ml}$ each) in the absence or presence of Glassia $(0.5 \mathrm{mg} / \mathrm{ml})$. As shown in Fig. 1A, 48 hours after stimulation islet viability was reduced, as expected, in the presence of IL- $1 \beta / \mathrm{IFN} \gamma(78 \pm 0.01 \%$ viability compared with non-stimulated islets, albeit without reaching statistical significance). However, in the presence of Glassia, islet viability was significantly improved and restored to near control levels. Accordingly, levels of insulin per islet released into the supernatants were significantly diminished by IL- $1 \beta /$ IFN $\gamma$-stimulation (a reduction of $3.67 \pm 0.05$-fold from nonstimulated islets) and significantly increased in stimulated islets $2.21 \pm 0.36$-fold in the presence of Glassia.

We next examined whether the changes in the levels of inducible inflammatory mediators that are released by islet cells, namely, nitrite oxide, IL-6, and MCP-1, and of the antiinflammatory mediator IL-10, are consistent with changes observed in previous reports. Indeed, as shown in Fig. 1B, nitric oxide production levels were increased by IL- $1 \beta / \mathrm{IFN} \gamma$ $5.48 \pm 0.51$-fold, unless Glassia was added, which resulted in a significant $32.3 \%$ decline in nitric oxide levels on average. Treatment with Glassia also reduced MCP-1 levels (33.8 \pm $0.07 \%$ from stimulated levels) and IL- 6 levels ( $52.9 \pm 0.10 \%$ from stimulated levels). Although IL-10 levels increased in the presence of IL- $1 \beta / \mathrm{IFN} \gamma$, its levels further increased 4.6 -fold in the presence of added Glassia.

To assess whether Glassia alters dendritic cell maturation as reported using other preparations of hAAT, cultured bone marrow-derived dendritic cells were treated with IL-1 $\beta$ $(5 \mathrm{ng} / \mathrm{ml})$ and IFN $\gamma(5 \mathrm{ng} / \mathrm{ml})$ in the absence or presence of Glassia $(0.5 \mathrm{mg} / \mathrm{ml})$ and were then examined for surface activation markers by flow cytometry. As shown in Fig. 1C, stimulated dendritic cells exhibited a marked rise in maturation markers CD86 and MHC class II; however, Glassia treatment resulted in diminished surface CD86 expression (51.4\% from stimulated levels, mean), and surface MHC class II reached $13.1 \pm 0.11 \%$, nearing control nonstimulated levels.

Glassia Treatment and Mouse Islet Allograft Survival. Islet graft survival was examined under the treatment of $60 \mathrm{mg} / \mathrm{kg}$ Glassia based on previous protocols (Fig. 2A). To avoid mouse anti-human antibody response, mice that are heterozygous for lung-specific human AAT and that display undetectable circulating levels of human AAT were used as
Islets

A
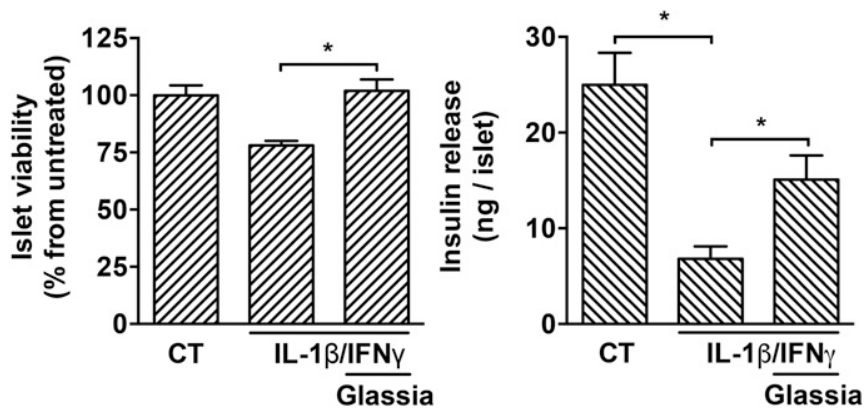

B
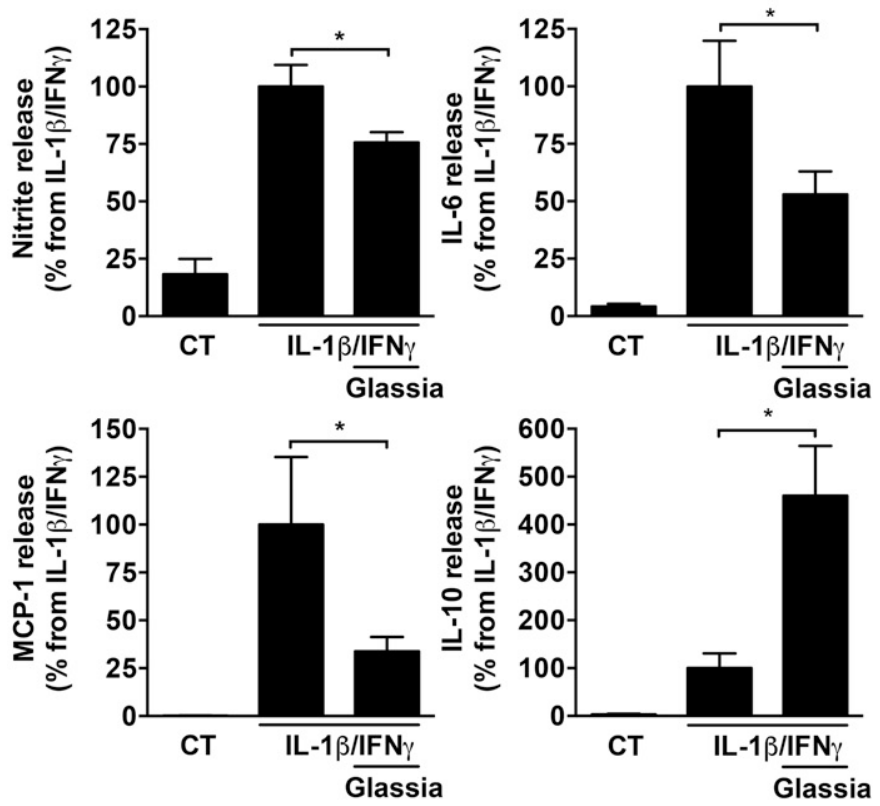

\section{Dendritic cells}

C
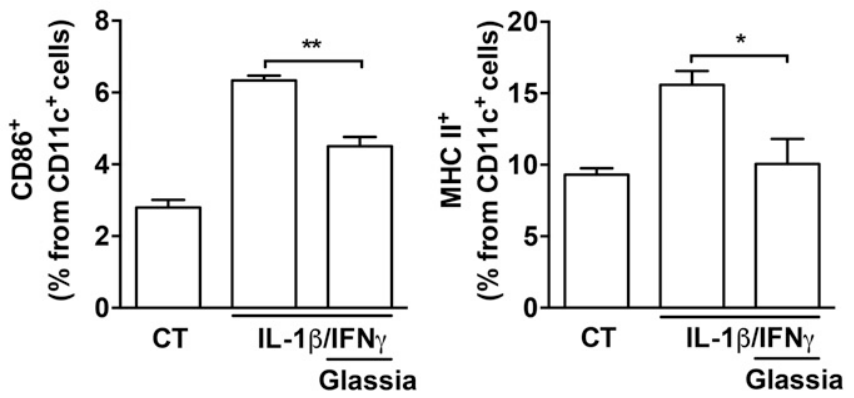

Fig. 1. The effect of Glassia on pancreatic islet responses and dendritic cell maturation during inflammatory conditions. (A and B) Primary mouse islets ( 35 per well in triplicate) were cultured for 48 hours in the absence (CT) or presence of IL- $1 \beta$ and IFN $\gamma(5 \mathrm{ng} / \mathrm{ml}$ each), with or without overnight pretreatment with Glassia $(0.5 \mathrm{mg} / \mathrm{ml})$. (A) Islet viability and insulin release. (B) Supernatant levels of nitric oxide, IL-6, MCP-1, and IL-10. (C) BMDCs $\left(3 \times 10^{5}\right.$ cells per well in triplicates) were stimulated with IL- $1 \beta$ and $\operatorname{IFN} \gamma(5 \mathrm{ng} / \mathrm{ml}$ each) overnight in the presence or absence of Glassia $(0.5 \mathrm{mg} / \mathrm{ml})$. Cells were analyzed by flow cytometry. Representative results of three independent experiments. Mean \pm S.E.M., ${ }^{*} P<0.05,{ }^{*} P<0.01$. 
graft recipients. Islet graft survival was defined as the duration of normoglycemia after transplantation, and rejection day was defined as the day circulating glucose levels exceeded $300 \mathrm{mg} / \mathrm{dl}$. Indefinite islet graft survival was defined as normoglycemia in grafted animals that lasted $>90$ days.

Here, doses were extended above and below $60 \mathrm{mg} / \mathrm{kg}$ with adherence to a uniform time course $(15,30,60,120$, and $240 \mathrm{mg} / \mathrm{kg}$, every 3 days beginning 1 day before transplantation). As shown, islet grafts in all untreated recipients (CT; Fig. 2A) failed to normalize blood glucose levels before day $20(n=9)$. Coinciding with previous reports,

A
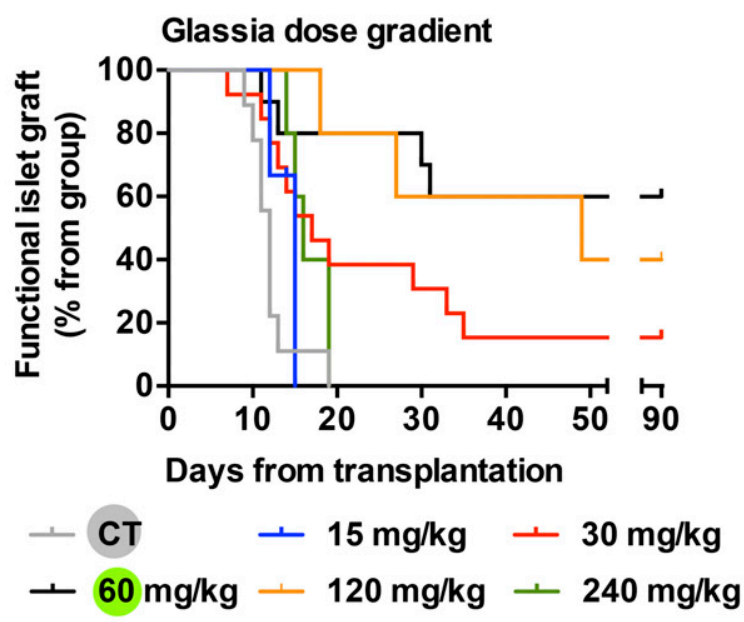

B

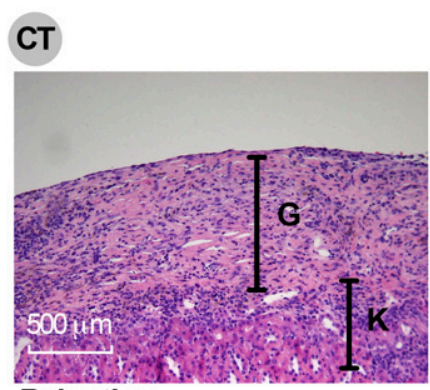

Rejection

\section{Glassia 60 mg/kg i.p.}

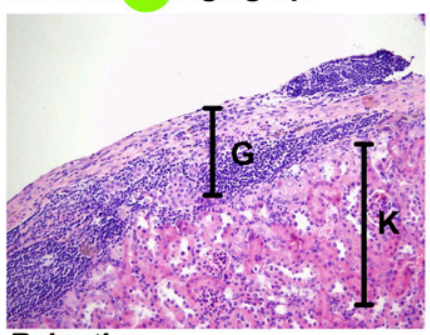

Rejection

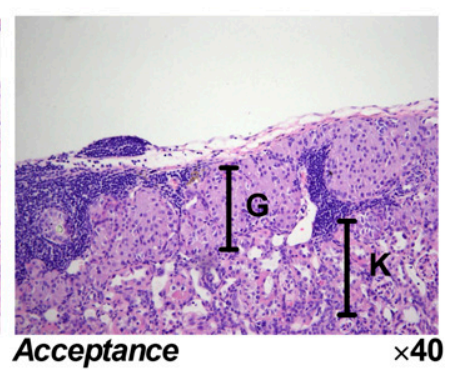

Acceptance administration of $60 \mathrm{mg} / \mathrm{kg}$ hAAT resulted in prolonged graft survival (indefinite graft acceptance in 6 of 10 mice). As expected, the extremely low dose of $15 \mathrm{mg} / \mathrm{kg}$ exhibited no protective effect on islet allografts, all transplants failed by day $15(n=3)$. The dose of $30 \mathrm{mg} / \mathrm{kg}$ resulted in a somewhat limited protection, achieving 2 of 13 mice with indefinite graft acceptance. As expected, twice the standard dose $(120 \mathrm{mg} / \mathrm{kg})$ achieved islet graft survival rates that were comparable to the $60 \mathrm{mg} / \mathrm{kg}$ group (2 of 5 grafts displayed indefinite graft function). Unexpectedly, the $240 \mathrm{mg} / \mathrm{kg}$ dose had no beneficial effect in the long term, because all grafts failed by day 20 $(n=5)$; nonetheless, the median time point of graft rejection was delayed to 16 days compared with the CT group median time to graft failure (12 days), and the earliest failing graft was on day 14 compared with day 9 in CT, indicating superior early graft function (Table 1).

Graft histology is depicted in Fig. 2B. As shown, rejected grafts in the CT group displayed subcapsular islet graft regions $(\mathrm{G})$ and kidney parenchyma $(\mathrm{K})$ with the prominent presence of a mononuclear infiltrate (representative image, 2 days after graft failure). Upon examining hAAT-treated mice, two patterns emerged: those that were explanted upon graft rejection and those that were accepted. As expected, hAAT-treated graft-rejected mice displayed robust cellular infiltrate throughout the graft site (representative image from the $60 \mathrm{mg} / \mathrm{kg}$ group 2 days after graft failure). However, indefinitely accepted grafts exhibited intact islet morphology with no evidence for cellular infiltrate within islet borders but rather a prominent noninvasive concentration of mononuclear cells at junctions of capsule-graft-kidney parenchyma (shown in representative day 110 explant), agreeing with the distinctive profile of active long-term immune tolerance.

Exploration of Transplantation Outcomes using a Fixed Dose of Glassia with Altered Frequency of Rationed Injections. In light of the outcomes in the dosescreening experiment, we sought to examine the impact of hAAT treatment using distinct layouts of dose rations. Namely, we sought to better emulate the behavior of circulating hAAT during an acute phase response, i.e., stably elevated levels and not fluctuating levels obtained during exogenous hAAT treatment. In addition, the pharmacokinetics of oddly distributed injections of hAAT in mice has yet to be determined. Here, mice received either single dose of $60 \mathrm{mg} / \mathrm{kg}$ i.p or the same total amount of hAAT distributed as two or three separate rations. Tail blood was collected and serum hAAT levels were determined. As shown in Fig. 3A, the obtained mouse hAAT serum pharmacokinetics were similar to that reported in humans in that soon after administration circulating hAAT levels peaked $(1,348.38 \pm 247.11 \mu \mathrm{g} / \mathrm{ml})$, followed by dramatic reduction over the following 72 hours, reaching $103.98 \pm 31.67 \mu \mathrm{g} / \mathrm{ml}$.

Being that the sharp decline in circulating levels of exogenous hAAT upon each dose administration does not represent the physiologic pattern of circulating hAAT during acute phase responses, we sought to examine the possibility that injected hAAT is readily sequestered onto cell membranes. Here, C57BL/6 wild-type mice were treated with single-dose Glassia (240 mg/kg i.p). In half the groups, the peritoneal compartment was preconditioned using thioglycolate for 3 days so as to elicit activated immunocytes with more expressive membrane profiles. Sixteen hours later, lavaged cells were examined for membrane-associated hAAT levels by
Fig. 2. Protection of pancreatic islet allografts by Glassia. Mice were rendered hyperglycemic by single-dose STZ $(225 \mathrm{mg} / \mathrm{kg})$ and then subjected to islet allograft transplantation. Experimental groups included: $15 \mathrm{mg} / \mathrm{kg}(n=3), 30 \mathrm{mg} / \mathrm{kg}(n=13), 60 \mathrm{mg} / \mathrm{kg}(n=10), 120 \mathrm{mg} / \mathrm{kg}(n=5)$, and $240 \mathrm{mg} / \mathrm{kg}(n=5)$. Control group animals received PBS vehicle $(n=9)$. (A) Graft survival curve. (B) Graft site histology, K signifies kidney tissue and $\mathrm{G}$ signifies graft site. Representative images of rejected untreated mouse graft (top), $60 \mathrm{mg} / \mathrm{kg}$-treated rejected graft (bottom left), and accepted graft (bottom right). 
TABLE 1

Islet graft function parameters after hAAT treatment

\begin{tabular}{|c|c|c|c|c|c|c|}
\hline Treatment Type & Treatment Group (mg/kg) & $n$ & $\begin{array}{l}\text { Median Graft } \\
\text { Survival (days) }\end{array}$ & $\begin{array}{l}\text { Average Graft } \\
\text { Survival (days) }\end{array}$ & $\begin{array}{c}\text { Indefinite Graft } \\
\text { Survival (\% from group) }\end{array}$ & $\begin{array}{l}\text { First Occurrence of Graft } \\
\text { Failure (day from transplantation) }\end{array}$ \\
\hline \multirow[t]{6}{*}{ i.p. dose gradient } & Untreated & 9 & 12 & 12.1 & 0 & 9 \\
\hline & 15 & 3 & 14 & 13.6 & 0 & 12 \\
\hline & 30 & 13 & 17 & 29.6 & 15.3 & 7 \\
\hline & 60 & 10 & 90 & 62.5 & 60 & 11 \\
\hline & 120 & 5 & 48 & 54.6 & 40 & 18 \\
\hline & 240 & 5 & 16 & 16.6 & 0 & 14 \\
\hline \multirow[t]{2}{*}{ i.p. dose distribution } & $30 / 30$ & 6 & 15 & 18.3 & 0 & 7 \\
\hline & $20 / 20 / 20$ & 3 & 90 & 65.3 & 66.6 & 16 \\
\hline \multirow[t]{4}{*}{ s.c. } & 60 & 6 & 90 & 77.1 & 83.3 & 13 \\
\hline & $30 / 30$ & 5 & 20 & 31.4 & 20 & 11 \\
\hline & 30 & 2 & 15 & 15 & 0 & 14 \\
\hline & 15 & 1 & 17 & 17 & 0 & 17 \\
\hline \multirow[t]{2}{*}{ dynamic dose } & $240 \rightarrow 0$ i.p. & 6 & 40 & 48.3 & 33.3 & 14 \\
\hline & $240 \rightarrow 0$ s.c. & 3 & 17 & 40.3 & 33.3 & 14 \\
\hline
\end{tabular}

flow cytometry. As shown in Fig. 1B, top, nonstimulated untreated mice (CT), as well as thioglycolate-preconditioned mice (ThG) displayed no detectible surface levels of hAAT. In contrast, thioglycolate-stimulated Glassia-treated mice (ThG/AAT) displayed detectible membrane-associated hAAT levels. Surprisingly, cells derived from nonstimulated Glassia-treated mice (AAT) did not show any detectible levels of hAAT.

The presence of cell-associated hAAT was also examined in cell lysates. For this, $1 \times 10^{6}$ peritoneal mouse macrophages were pulsed with $0.5 \mathrm{mg} / \mathrm{ml}$ Glassia in vitro and then washed with PBS after various time points. Upon lysis, levels of hAAT were evaluated by Western blot analysis. As shown in Fig. 1B, bottom, hAAT can be recovered from cell lysates as early as 5 minutes after treatment.

Different dose distribution protocols were compared: $\times 1$ of $60 \mathrm{mg} / \mathrm{kg}, \times 2$ of $30 \mathrm{mg} / \mathrm{kg}$, and $\times 3$ of $20 \mathrm{mg} / \mathrm{kg}$ within 72 hours. As shown in Fig. 3C, the $30 \mathrm{mg} / \mathrm{kg}$ dose displayed the predicted circulating levels of $667.05 \pm 117.95 \mu \mathrm{g} / \mathrm{ml}$ and a kinetic that overlaps the full dose, and the additional dose of $30 \mathrm{mg} / \mathrm{kg}$ increased circulating hAAT levels to $976.1 \pm 221.03 \mu \mathrm{g} / \mathrm{ml}$ and a value of $69.32 \mu \mathrm{g} / \mathrm{ml}$ hAAT at the lowest measurement. However, administration of Glassia at $20 \mathrm{mg} / \mathrm{kg}$ every 24 hours over a period of 3 days resulted in a relatively stable range of concentrations, all above $226.65 \mu \mathrm{g} / \mathrm{ml}$ hAAT.

The ability of these dose distribution protocols to prolong islet graft survival was next examined. As shown in Fig. 3D, administration of Glassia at $30 \mathrm{mg} / \mathrm{kg}$ every 36 hours had a minor effect on graft survival, and all mice rejected the grafts by day $40(n=6)$. Surprisingly, when mice were treated with daily $20 \mathrm{mg} / \mathrm{kg}$ doses, $66 \%$ displayed indefinite graft survival, comparable to the $60 \mathrm{mg} / \mathrm{kg}$ group $(n=3)$. Table 1 depicts the influence of dose distribution on islet allograft survival.

Subcutaneous Administration of Glassia. Because the somewhat uniform distribution of hAAT appears to have provided a positive trend in as far as islet protection, using a lower dose per injection, we explored subcutaneous administration of hAAT as a clinically-favorable route that results in a relatively slow release of injected material. As shown in Fig. 4A, circulating hAAT was distributed along the 72-hour experiment in a distinct manner based on the frequency of injected material. The standard dose of $60 \mathrm{mg} / \mathrm{kg}$ displayed a delayed peak followed by a gradual decrease. The $20 \mathrm{mg} / \mathrm{kg}$ dose was tested alone, and in a serial manner that reaches the same total of $60 \mathrm{mg} / \mathrm{kg}$ per 72 hours; as shown, single dose $20 \mathrm{mg} / \mathrm{kg}$ conforms well to the pattern obtained with $60 \mathrm{mg} / \mathrm{kg}$ s.c.. However, daily administration of $20 \mathrm{mg} / \mathrm{kg}$ over 3 days resulted in a well-anticipated build-up of circulating hAAT followed by stabilization at 601.27 $\pm 6.232 \mu \mathrm{g} / \mathrm{ml}$.

The effect of switching to the subcutaneous route of administration on islet graft survival was next examined (Fig. 4B). Compared with the established outcomes of intraperitoneal administration of Glassia, graft survival profile was superior in the $60 \mathrm{mg} / \mathrm{kg}$ s.c. group alone and to a lesser extent in the $\times 2$ of $30 \mathrm{mg} / \mathrm{kg}$ group. The rest of the subcutaneous dosing protocols resulted in grafts failing by day 40 with no apparent advantage over intraperitoneal injections of equivalent doses, as summarized in Table 1.

Dynamic versus Static Dose Protocol. Based on an apparent benefit to high dose Glassia $(240 \mathrm{mg} / \mathrm{kg}$ ) on early graft function and the benefit of lower doses thereafter $(\times 3$ of $20 \mathrm{mg} / \mathrm{kg}$ ), we were interested in examining whether their incorporation into a short dynamic-dose protocol may prolong graft survival in a manner superior to the flat $60 \mathrm{mg} / \mathrm{kg}$ dose plan. Figure 5A displays the treatment plan, which runs through days -1 to 7 from islet grafting, in descending doses. The rationale for cutting the treatment short was to facilitate the isolation of any potential advantage of the examined course of treatment over the standard prolonged $60 \mathrm{mg} / \mathrm{kg}$ plan. In addition, the subcutaneous route was compared with the intraperitoneal route.

As shown in Fig. 5B, both routes of administration of the descending dynamic dose resulted in outcomes that were comparable to the $60 \mathrm{mg} / \mathrm{kg}$ dose in the first 3 weeks of treatment, at which point, unexpectedly, a week of dynamic $240-60 \mathrm{mg} / \mathrm{kg}$ i.p. Glassia remained beneficial to islet function almost as favorably as the $60 \mathrm{mg} / \mathrm{kg}$ dose (days 14, 16, 31, $49,>90$, and $>90$ ). In contrast, subcutaneous administration of descending hAAT doses displayed a trend toward grafts failing before the 3 -week time point (days 14, 17, and $>90$ ). A similar survival trend was observed in the subcutaneous group, $33 \%$ of mice displayed graft survival beyond day 90 . Table 1 lists the parameters of comparison between treatment groups.

\section{Discussion}

Human $\alpha 1$-antitrypsin has been extensively investigated in preclinical models of autoimmune diabetes and islet allograft transplantation. Administered in the early stages of these 
A

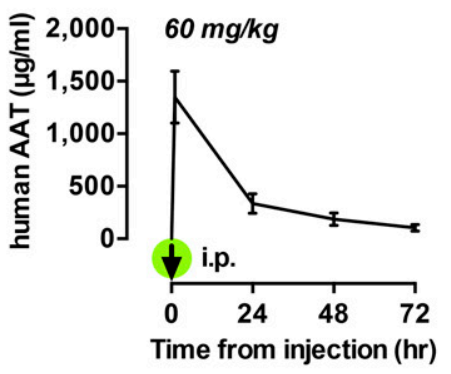

B

a

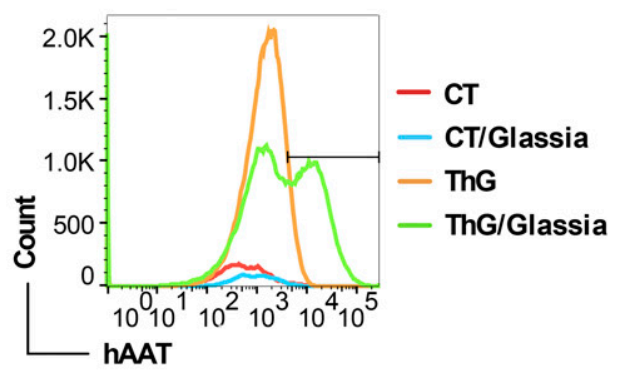

b

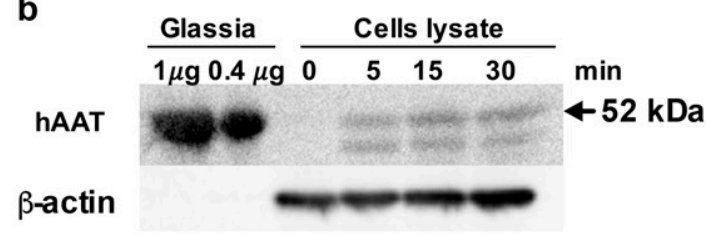

C

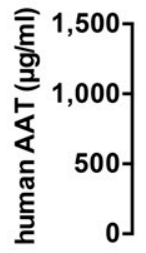

$30 / 30 \mathrm{mg} / \mathrm{kg}$

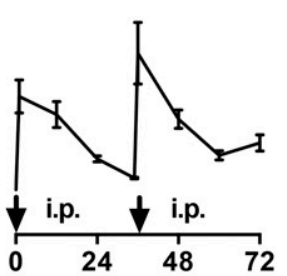

Time from injection (hr)

D
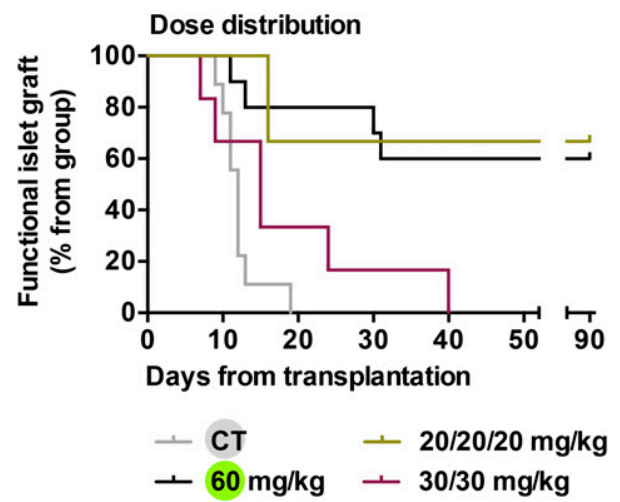

Fig. 3. The effect of intraperitoneal Glassia dose distribution treatment on hAAT serum concentration and islet graft survival. (A) Mice $(n=3-5)$ were treated with $60 \mathrm{mg} / \mathrm{kg}$ i.p Glassia as indicated (arrow). Serum levels of human AAT were determined with specific ELISA. Results of 3 independent experiments, mean \pm S.E.M. (B) Mice were stimulated with ThG for 72 hours after treatment with Glassia $(240 \mathrm{mg} / \mathrm{kg}$ i.p.). Peritoneal lavage was performed 16 hours later, and membraneassociated hAAT levels were measured by flow cytometry (top panel). Groups included nonstimulated, untreated mice (CT, red); ThG- pathologies, hAAT appears to shift the profile of the immune system toward tolerance (Lewis et al., 2008a; Koulmanda et al., 2014). These studies provided the rationale for the use of hAAT infusions for patients with T1D (Gottlieb et al., 2014; Rachmiel et al., 2016) and for clinical islet transplantation, as reviewed (Fleixo-Lima et al., 2014).

The dosing for these studies is directly extracted from lifelong hAAT augmentation protocols, designed for patients with genetic AATD. However, these doses are not based on preclinical data, let alone on the specific purpose of protecting islet cells from injury. Specific attention to functional endpoints, e.g., islet cell viability, has yet to be incorporated. Here, we examined the effect of hAAT (Glassia) on mouse islet function and survival both in vitro and in vivo at a wide range of clinically relevant doses and routes of administration. As expected, treatment with Glassia reproduced the previously reported beneficial outcomes using other clinical-grade formulations (e.g., Aralast, Baxter Deerfield, IL; Pileggi et al., 2008; Koulmanda et al., 2012; Koulmanda et al., 2014); islet viability and function had increased, their inflammatory profile decreased, and graft survival was prolonged.

The rationale for exploring not only the dose but also the distribution of doses relates to the dynamic of islet injury. After islet transplantation, grafts endure nonspecific inflammation and subsequently only are destroyed by antigen-specific events; the early phase is as crucial to islet function as the latter. By following the function of grafted islets, we identify both phases of islet injury. As expected, not all doses of hAAT effectively targeted both waves of islet destruction; lower doses were inefficient altogether and the $120 \mathrm{mg} / \mathrm{kg}$ dose provided no particular benefit over $60-80 \mathrm{mg} / \mathrm{kg}$ dose. The high dose of $240 \mathrm{mg} / \mathrm{kg}$, confirmed to be safe in animals (Ashkenazi et al., 2013; Iskender et al., 2016) and patients (Stolk et al., 2005), displayed an advantage in protecting islets in the first 14 days from grafting; it failed, however, to provide long-lasting benefit, possibly by facilitating concentration-dependent allogeneic mouse anti-human antibodies (Lewis et al., 2005; Lu et al., 2006). Of note, several treatment groups have a low $n$, including groups treated with extreme subtherapeutic doses of hAAT previously shown to fail in protecting allografts (Shahaf et al., 2011). Thus these particular group outcomes satisfy dose dependency curves rather than novelty.

Based on these observations, we examined the outcomes of a dynamic dose treatment. Exploiting both the favorable effects of an initial high dose of hAAT and the advantage of lower maintenance doses thereafter, a relatively short descending treatment protocol was tested $(240 \rightarrow 120 \rightarrow 60 \rightarrow 60)$. This protocol offered prolonged islet graft survival similar to repeated indefinite injections of $60 \mathrm{mg} / \mathrm{kg} \mathrm{hAAT}$. The fact that a longstanding immune tolerance has thus far required at least

stimulated untreated mice (ThG, yellow); nonstimulated Glassia-treated mice (CT/Glassia, blue), and ThG-stimulated Glassia-treated mice (ThG/Glassia, green), $n=3$. Results are representative of 3 independent repeats. For cell-associated analysis (bottom panel), peritoneal macrophages $\left(1 \times 10^{6}\right.$, in triplicate) were pulsed with Glassia $(0.5 \mathrm{mg} / \mathrm{ml})$. hAAT binding was evaluated by Western blotting. (C) Mice were treated with $30 \mathrm{mg} / \mathrm{kg}$ (left) or $20 \mathrm{mg} / \mathrm{kg}$ (right) Glassia intraperitoneally at indicated time points (arrow; $n=3$ or 4 in each group). Serum levels of human AAT were determined. Results of 3 independent experiments, mean \pm S.E.M. (D) Islet graft survival curve. Groups include: $\times 3$ of $20 \mathrm{mg} / \mathrm{kg}$ i.p $(n=3$, yellow) and $\times 2$ of $30 \mathrm{mg} / \mathrm{kg}$ i.p $(n=6$, red). CT and $60 \mathrm{mg} / \mathrm{kg}$ treatment groups are duplicates of Fig. 2A. 
A Glassia s.c.
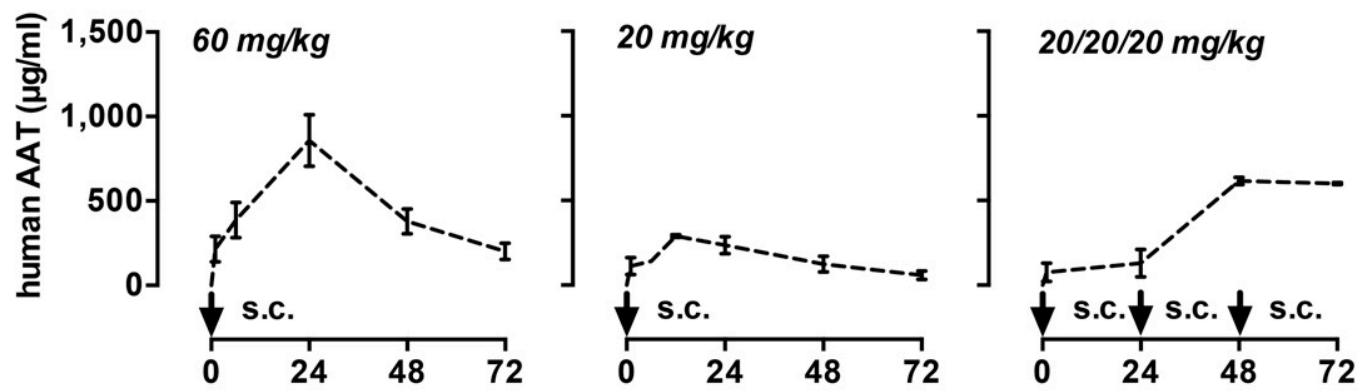

Time from injection (hr)

\section{B Glassia s.c. versus i.p.}
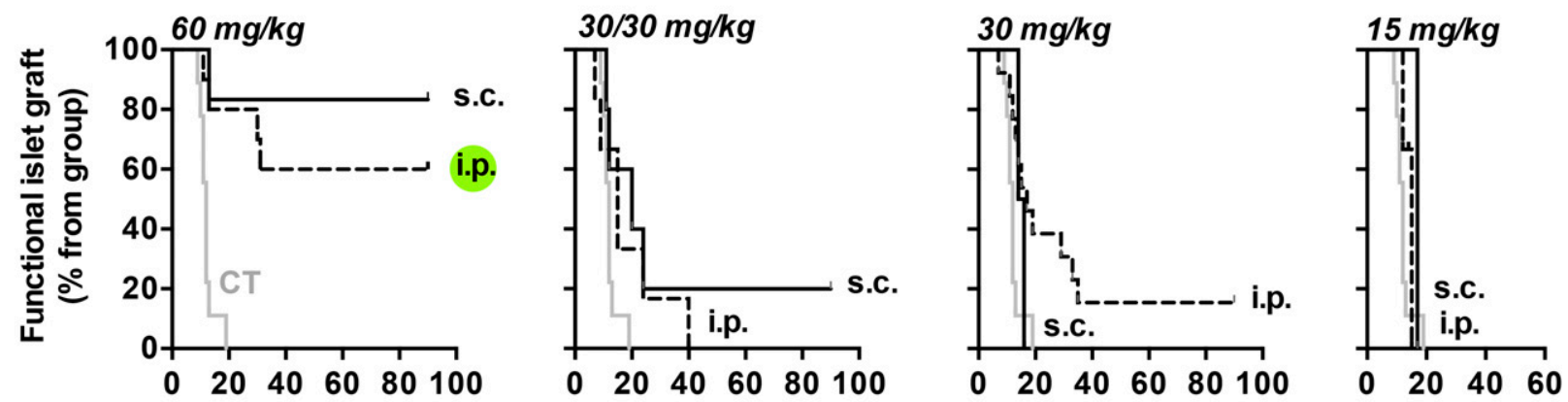

\section{Days from transplantation}

Fig. 4. The effect of subcutaneous Glassia treatment on hAAT serum concentration and islet graft survival. (A) Mice were treated with 60 and $20 \mathrm{mg} / \mathrm{kg}$ Glassia subcutaneously at indicated time points (arrow; $n=3$ or 4 in each group). Serum hAAT levels were measured. Results are representative of three independent experiments, mean \pm S.E.M. (B) Islet grafted mice were treated with Glassia either intraperitoneally (dashed) or subcutaneously (solid). Groups include untreated mice (CT; gray. $n=9) ; \times 1 \mathrm{of} 60 \mathrm{mg} / \mathrm{kg}$ i.p $(n=10) ; \times 1 \mathrm{of} 60 \mathrm{mg} / \mathrm{kg} \mathrm{s.c}(n=6) ; \times 2 \mathrm{of} 30 \mathrm{mg} / \mathrm{kg}$ i.p. $(n=6) ; \times 2$ of $30 \mathrm{mg} / \mathrm{kg} \mathrm{s.c.}(n=5) ; \times 1$ of $30 \mathrm{mg} / \mathrm{kg}$ i.p $(n=13) ; \times 1 \mathrm{of} 30 \mathrm{mg} / \mathrm{kg}$ s.c. $(n=2) ; \times 1 \mathrm{of} 15 \mathrm{mg} / \mathrm{kg}$ i.p $(n=3) ; \times 1 \mathrm{of} 15 \mathrm{mg} / \mathrm{kg} \mathrm{s.c.}(n=1)$. Islet graft survival curve.

21 days of repeated $60 \mathrm{mg} / \mathrm{kg}$ hAAT in mice (Lewis et al., 2008a) and is achieved hereby in a short dynamic protocol, sheds light on the importance of peritransplantation protection of islets compared with the finer immunomodulation by hAAT that occurs thereafter and may require low doses.

Unlike during acute phase responses, where hAAT levels rise progressively, patient infusions result in nonphysiologic spikes in circulating hAAT. To better imitate the physiologic pattern, we examined variations in dose distribution. As we demonstrate here, dividing $60 \mathrm{mg} / \mathrm{kg}$ dose of hAAT to $30 / 30$ and to $20 / 20 / 20 \mathrm{mg} / \mathrm{kg}$ injections within the same original timeframe resulted in an interesting phenomenon: when it comes to protection of islet grafts from failure, i.e., the desired outcome/activity of hAAT treatment in the present constellation, the presence of mildly elevated stable circulating hAAT levels (20/20/20 i.p.) was superior to the 30/30 i.p. dose distribution; the latter displayed transient periods of low circulating hAAT levels between injections. Nonetheless, it is established that patient compliance is already inferior in weekly infusion-drip sessions compared with other forms of administration, let alone to more frequent infusions; excluding recent positive hAAT gene therapy attempts (Flotte et al., 2011), there is presently no protocol for systemic administration of hAAT in any other manner outside weekly infusions.
In as far as achieving the desired outcome for augmentation therapy, hAAT infusion appeared thus far to be sufficient, i.e., it reduced the risk for pulmonary emphysema (Balbi et al., 2016). Here, the desired endpoint is distinct and might not be the mere amount of circulating hAAT; rather, we propose that it is its levels between infusions. Thus we explored subcutaneous hAAT; by this we also achieve a slower deposition of hAAT in the serum. Interestingly, subcutaneous is preferable in a list of drugs that used to be administered intravenously/intramuscularly, including heparin and hydrocortisone (Jin et al., 2015). However here, only the $60 \mathrm{mg} / \mathrm{kg}$ group displayed prolong graft survival. In the parallel intraperitoneal route of administration, only the $60 \mathrm{mg} / \mathrm{kg}$ and the $20 / 20 / 20 \mathrm{mg} / \mathrm{kg}$ groups displayed prolonged graft survival. These groups have also displayed higher levels of hAAT in the serum $(\sim 1 \mu \mathrm{g} / \mathrm{ml})$, similar only to the $60 \mathrm{mg} / \mathrm{kg}$ s.c group. Thus it is possible that other groups failed to reach therapeutic levels early after transplantation. Considering this dose would translate to an impractical volume of subcutaneous material for human injection (Jin et al., 2015), this outcome suggests that a more concentrated formulation of clinical-grade hAAT, or a slow-release apparatus, may better emulate sustained functional levels of hAAT. The prospect of introducing hAAT subcutaneously has been tested in rabbits (Pamarthi et al., 


\section{A Dynamic dose}

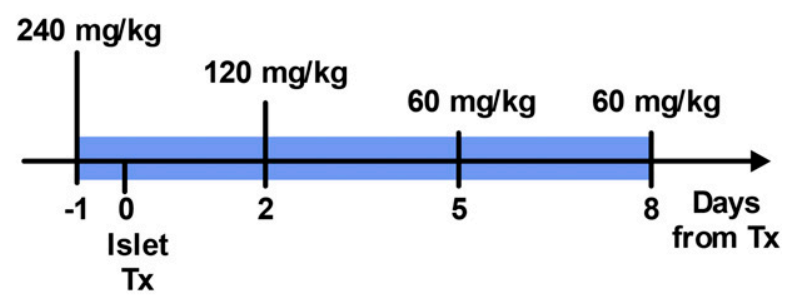

B Dynamic vs. static dose

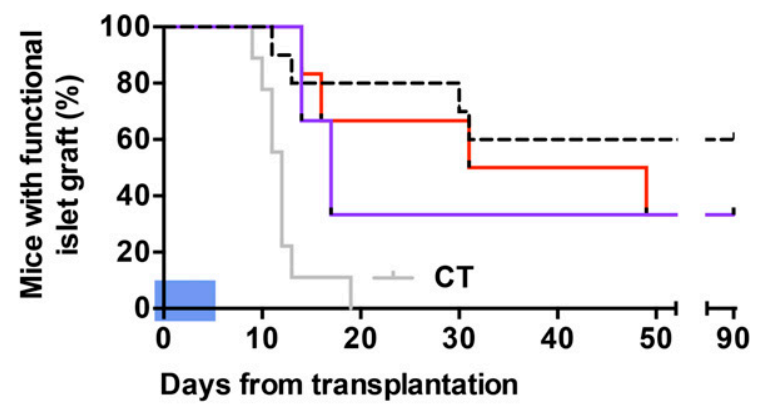

$$
\text { Static dose: }--60 \mathrm{mg} / \mathrm{kg} \quad 240 \rightarrow 0 \mathrm{mg} / \mathrm{kg}\left[\begin{array}{l}
- \text { i.p. } \\
- \text { s.c. }
\end{array}\right.
$$

Fig. 5. The effect of Glassia dynamic dose treatment on graft survival. Islet-grafted mice were treated with Glassia using dynamic dose regimen. (A) Illustration representing the treatment protocol. (B) Islet graft survival curve under Glassia dynamic dose treatment (blue area). Comparison of intraperitoneal (red; $n=6$ ) and subcutaneous (purple; $n=3$ ) dynamic dose treatment.

2008) and mice (Ma et al., 2010) and is evaluated in a phase I/II trial (NCT02503683).

The anti-inflammatory mechanism of hAAT is not entirely clear. Regarding signal transduction, hAAT was reported to elevate cAMP levels in multiple cell types (Janciauskiene et al., 2007; Kalis et al., 2010; Ehlers, 2014) and in this manner is associated with an anti-inflammatory profile (Tilg et al., 1993; Pott et al., 2009). We hypothesize that it is not merely the antiprotease function of hAAT that exerts beneficial effects on islet survival but rather multiple binding activities that were recently described for the molecule, as reviewed in (Guttman et al., 2015). Jonigk et al. (2013) report that hAAT with no antielastase activity reduces responses to lipopolysaccharide. Here we show that exogenous hAAT adheres to immune cells, agreeing with reports of adherence of hAAT to membrane lipid rafts (Subramaniyam et al., 2010; Zhou et al., 2015). Binding to cell surfaces would also provide a mechanism for the rapid sequestration of exogenous hAAT and the superiority of continuously elevated hAAT over interspersed spikes, agreeing with islet preservation using plasmid-derived hAAT in vivo (Lu et al., 2006; Shahaf et al., 2011).

Other binding targets of hAAT include a set of dangerassociated molecular pattern molecules (DAMPs), which predominate at sites of cell injury and act as immune adjuvants (Braza et al., 2016), including gp96 and HSP70 (Finotti and Pagetta, 2004; Ochayon et al., 2013). Based on this attribute, it is possible that the narrow surge in hAAT levels would be inferior to its constant supply, in a manner that accommodates local DAMP sequestration. It also supports the concept of a dynamic dose, in that the expected period of peak DAMPs would be the earlier window of massive cell injury, as opposed to the more delicate manipulation of immunocyte functions (Ozeri et al., 2012). Indeed, some overlap between the pathophysiology of emphysema and T1D may exist: lung alveolar wall degradation is observed in AATD and $\beta$ cell injury in T1D is associated with inactivated glycated-hAAT (Austin et al., 1987).

How does the present study translate to humans? Administering hAAT to humans once a week is the equivalent of administering hAAT to mice every 3 days (Lewis et al., 2005). Based on this frequency of infusions, 21 days of treatment (6 infusions in mice) were established as sufficient to achieve immune tolerance (Lewis et al., 2008a), hence the 8-18 infusions in the T1D trials (Gottlieb et al., 2014; Rachmiel et al., 2016). Based on the present results, however, it is possible that future trials may explore a shorter course of hAAT, provided it is distributed so as to better overlap a physiologic acute phase response. For example, patients may be introduced the following course of weekly hAAT infusions: $180,180,120,120,120,120,60$, and $60 \mathrm{mg} / \mathrm{kg}$ (all representing slow-drip infusion sessions in recently diagnosed patients with high titers of auto-antibodies and detectable c-peptide levels). This shorter protocol may be both more potent in immediate islet protection and superior in as far as patient compliance and procedure cost.

Taken together, we provide a platform for extrapolation of a clinical protocol from animals in which hAAT appears to protect islets from injury. The study places emphasis on function- and outcome-oriented analyses of treatment, a particularly important entity when considering that hAAT is entering an era of drug-repurposing toward an extended list of clinical indications (Lewis, 2012; Lior et al., 2016). More studies are to be undertaken to optimize treatment protocols relevant to diseases other than AATD.

\section{Authorship Contributions}

Participated in research design: Baranovski, Ozeri, Strauss, Schenker, and Lewis.

Conducted experiments: Baranovski, Ozeri, Shahaf, Ochayon, Schuster, Bahar, Kalay, Cal, and Mizrahi.

Contributed new reagents or analytic tools: Strauss and Schenker. Performed data analysis: Baranovski, Ozeri, and Lewis.

Wrote or contributed to the writing of the manuscript: Baranovski, Ozeri, Nisim, Strauss, Schenker, and Lewis.

\section{References}

Ashkenazi E, Baranovski BM, Shahaf G, and Lewis EC (2013) Pancreatic islet xenograft survival in mice is extended by a combination of alpha-1-antitrypsin and single-dose anti-CD4/CD8 therapy. PLoS One 8:e63625.

Austin GE, Mullins RH, and Morin LG (1987) Non-enzymic glycation of individual plasma proteins in normoglycemic and hyperglycemic patients. Clin Chem 33: $2220-2224$

Balbi B, Ferrarotti I, and Miravitlles M (2016) Efficacy of augmentation therapy for emphysema associated with $\alpha 1$-antitrypsin deficiency: enough is enough. Eur Respir J 47:35-38.

Braza F, Brouard S, Chadban S, and Goldstein DR (2016) Role of TLRs and DAMPs in allograft inflammation and transplant outcomes. Nat Rev Nephrol 12:281-290. Daemen MA, Heemskerk VH, van't Veer C, Denecker G, Wolfs TG, Vandenabeele P, and Buurman WA (2000) Functional protection by acute phase proteins alpha(1)acid glycoprotein and alpha(1)-antitrypsin against ischemia/reperfusion injury by preventing apoptosis and inflammation. Circulation 102:1420-1426.

Dhami R, Zay K, Gilks B, Porter S, Wright JL, and Churg A (1999) Pulmonary epithelial expression of human alpha1-antitrypsin in transgenic mice results in delivery of alpha1-antitrypsin protein to the interstitium. J Mol Med (Berl) $\mathbf{7 7}$ : $377-385$.

Ehlers MR (2014) Immune-modulating effects of alpha-1 antitrypsin. Biol Chem 395: 1187-1193.

Elshikha AS, Lu Y, Chen MJ, Akbar M, Zeumer L, Ritter A, Elghamry H, Mahdi MA, Morel L, and Song S (2016) Alpha 1 antitrypsin inhibits dendritic cell activation and attenuates nephritis in a mouse model of lupus. PLoS One 11:e0156583. 
Feng Y, Hu L, Xu Q, Yuan H, Ba L, He Y, and Che H (2015) Cytoprotective role of alpha-1 antitrypsin in vascular endothelial cell under hypoxia/reoxygenation condition. J Cardiovasc Pharmacol 66:96-107.

Feng Y, Xu J, Zhou Q, Wang R, Liu N, Wu Y, Yuan H, and Che H (2016) Alpha-1 antitrypsin prevents the development of preeclampsia through suppression of oxidative stress. Front Physiol 7:176.

Finotti P and Pagetta A (2004) A heat shock protein70 fusion protein with alpha1antitrypsin in plasma of type 1 diabetic subjects. Biochem Biophys Res Commun 315:297-305.

Fleixo-Lima G, Ventura H, Medini M, Bar L, Strauss P, and Lewis EC (2014) Mechanistic evidence in support of alpha1-antitrypsin as a therapeutic approach for type 1 diabetes. J Diabetes Sci Technol 8:1193-1203.

Flotte TR, Trapnell BC, Humphries M, Carey B, Calcedo R, Rouhani F, CampbellThompson M, Yachnis AT, Sandhaus RA, McElvaney NG, et al. (2011) Phase 2 clinical trial of a recombinant adeno-associated viral vector expressing $\alpha 1$-antitrypsin: interim results. Hum Gene Ther 22:1239-1247.

Gao W, Zhao J, Kim H, Xu S, Chen M, Bai X, Toba H, Cho HR, Zhang H, Keshavjeel $\mathrm{S}$, et al. (2014) alpha1-Antitrypsin inhibits ischemia reperfusion-induced lung injury by reducing inflammatory response and cell death. $J$ Heart Lung Transplant 33:309-315.

Gottlieb PA, Alkanani AK, Michels AW, Lewis EC, Shapiro L, Dinarello CA, and Zipris D (2014) $\alpha 1$-Antitrypsin therapy downregulates toll-like receptorinduced IL-1 $\beta$ responses in monocytes and myeloid dendritic cells and may improve islet function in recently diagnosed patients with type 1 diabetes. $J$ Clin Endocrinol Metab 99:E1418-E1426.

Grimstein C, Choi YK, Satoh M, Lu Y, Wang X, Campbell-Thompson M, and Song S (2010) Combination of alpha-1 antitrypsin and doxycycline suppresses collageninduced arthritis. J Gene Med 12:35-44.

Guttman O, Baranovski BM, Schuster R, Kaner Z, Freixo-Lima GS, Bahar N, Kalay N, Mizrahi MI, Brami I, Ochayon DE, et al. (2015) Acute-phase protein $\alpha 1$-antitrypsin: diverting injurious innate and adaptive immune responses from nonauthentic threats. Clin Exp Immunol 179:161-172.

Iskender I, Sakamoto J, Nakajima D, Lin H, Chen M, Kim H, Guan Z, Del Sorbo L, Hwang D, Waddell TK, et al. (2016) Human $\alpha 1$-antitrypsin improves early posttransplant lung function: Pre-clinical studies in a pig lung transplant model. $J$ Heart Lung Transplant 35:913-921.

Janciauskiene SM, Nita IM, and Stevens T (2007) Alpha1-antitrypsin, old dog, new tricks. Alpha1-antitrypsin exerts in vitro anti-inflammatory activity in human monocytes by elevating cAMP. J Biol Chem 282:8573-8582

Jin JF, Zhu LL, Chen M, Xu HM, Wang HF, Feng XQ, Zhu XP, and Zhou Q (2015) The optimal choice of medication administration route regarding intravenous, in tramuscular, and subcutaneous injection. Patient Prefer Adherence 9:923-942.

Jonigk D, Al-Omari M, Maegel L, Müller M, Izykowski N, Hong J, Hong K, Kim SH, Dorsch M, Mahadeva R, et al. (2013) Anti-inflammatory and immunomodulatory properties of $\alpha 1$-antitrypsin without inhibition of elastase. Proc Natl Acad Sci USA 110:15007-15012.

Kalis M, Kumar R, Janciauskiene S, Salehi A, and Cilio CM (2010) $\alpha$ 1-antitrypsin enhances insulin secretion and prevents cytokine-mediated apoptosis in pancreatic $\beta$-cells. Islets 2:185-189.

Koulmanda M, Bhasin M, Fan Z, Hanidziar D, Goel N, Putheti P, Movahedi B, Libermann TA, and Strom TB (2012) Alpha 1-antitrypsin reduces inflammation and enhances mouse pancreatic islet transplant survival. Proc Natl Acad Sci USA 109:15443-15448.

Koulmanda M, Sampathkumar RS, Bhasin M, Qipo A, Fan Z, Singh G, Movahedi B, Duggan M, Chipashvili V, and Strom TB (2014) Prevention of nonimmunologic loss of transplanted islets in monkeys. Am J Transplant 14:1543-1551.

Lewis EC (2012) Expanding the clinical indications for $\alpha(1)$-antitrypsin therapy. $M o$ Med 18:957-970.

Lewis EC, Mizrahi M, Toledano M, Defelice N, Wright JL, Churg A, Shapiro L, and Dinarello CA (2008a) alpha1-Antitrypsin monotherapy induces immune tolerance during islet allograft transplantation in mice. Proc Natl Acad Sci USA 105: $16236-16241$.

Lewis EC, Mizrahi M, Toledano M, Defelice N, Wright JL, Churg A, Shapiro L, and Dinarello CA (2008b) alpha1-Antitrypsin monotherapy induces immune tolerance during islet allograft transplantation in mice. Proc Natl Acad Sci USA 105 16236-16241.

Lewis EC, Shapiro L, Bowers OJ, and Dinarello CA (2005) Alpha1-antitrypsin monotherapy prolongs islet allograft survival in mice. Proc Natl Acad Sci USA 102 $12153-12158$
Lior Y, Geyra A, and Lewis EC (2016) Therapeutic compositions and uses of alpha1-antitrypsin: a patent review (2012 - 2015). Expert Opin Ther Pat 26: $581-589$

Lu Y, Tang M, Wasserfall C, Kou Z, Campbell-Thompson M, Gardemann T, Crawford J, Atkinson M, and Song S (2006) Alpha1-antitrypsin gene therapy modulates cellular immunity and efficiently prevents type 1 diabetes in nonobese diabetic mice. Hum Gene Ther 17:625-634.

Ma H, Lu Y, Li H, Campbell-Thompson M, Parker M, Wasserfall C, Haller M, Brantly M, Schatz D, Atkinson M, et al. (2010) Intradermal alpha1-antitrypsin therapy avoids fatal anaphylaxis, prevents type 1 diabetes and reverses hyperglycaemia in the NOD mouse model of the disease. Diabetologia 53:2198-2204.

Ochayon DE, Mizrahi M, Shahaf G, Baranovski BM, and Lewis EC (2013) Human $\alpha 1$ Antitrypsin Binds to Heat-Shock Protein gp96 and Protects from Endogenous gp96-Mediated Injury In vivo. Front Immunol 4:320.

Ozeri E, Mizrahi M, Shahaf G, and Lewis EC (2012) $\alpha-1$ antitrypsin promotes semimature, IL-10-producing and readily migrating tolerogenic dendritic cells. $J$ Immunol 189:146-153.

Pamarthi MF, Taylor GM, Wilson J, Scuderi P, and Arora V (2008) Pharmacokinetics of Subcutaneously Administered Alpha-1 Antitrypsin. J Allergy Clin Immunol 123: S163.

Pileggi A, Molano RD, Song S, Zahr E, SanJose S, Villate S, Wasserfall C, Ricordi C, Atkinson MA, and Inverardi L (2008) Alpha-1 antitrypsin treatment of spontaneously diabetic nonobese diabetic mice receiving islet allografts. Transplant Proc 40 $457-458$

Pott GB, Chan ED, Dinarello CA, and Shapiro L (2009) Alpha-1-antitrypsin is an endogenous inhibitor of proinflammatory cytokine production in whole blood. J Leukoc Biol 85:886-895.

Rachmiel M, Strauss P, Dror N, Benzaquen H, Horesh O, Tov N, Weintrob N, Landau Z, Ben-Ami M, Haim A, et al. (2016) Alpha-1 antitrypsin therapy is safe and well tolerated in children and adolescents with recent onset type 1 diabetes mellitus. Pediatr Diabetes 17:351-359.

Shahaf G, Moser H, Ozeri E, Mizrahi M, Abecassis A, and Lewis EC (2011) $\alpha-1$ antitrypsin gene delivery reduces inflammation, increases T-regulatory cell population size and prevents islet allograft rejection. Mol Med 17:1000-1011.

Sorrells S, Camprubi S, Griffin R, Chen J, and Ayguasanosa J (2015) SPARTA clinical trial design: exploring the efficacy and safety of two dose regimens of alpha1-proteinase inhibitor augmentation therapy in alpha1-antitrypsin deficiency. Respir Med 109:490-499.

Stolk J, Nieuwenhuizen W, Stoller JK, and Aboussouan L (2005) High dose intravenous AAT and plasma neutrophil derived fibrinogen fragments. Thorax 60:84.

Subramanian S, Shahaf G, Ozeri E, Miller LM, Vandenbark AA, Lewis EC, and Offner H (2011) Sustained expression of circulating human alpha-1 antitrypsin reduces inflammation, increases CD4+FoxP3+ Treg cell population and prevents signs of experimental autoimmune encephalomyelitis in mice. Metab Brain Dis 26 107-113.

Subramaniyam D, Zhou H, Liang M, Welte T, Mahadeva R, and Janciauskiene S (2010) Cholesterol rich lipid raft microdomains are gateway for acute phase protein, SERPINA1. Int J Biochem Cell Biol 42:1562-1570.

Tawara I, Sun Y, Lewis EC, Toubai T, Evers R, Nieves E, Azam T, Dinarello CA and Reddy P (2012) Alpha-1-antitrypsin monotherapy reduces graft-versus-host disease after experimental allogeneic bone marrow transplantation. Proc Natl Acad Sci USA 109:564-569.

Tilg H, Vannier E, Vachino G, Dinarello CA, and Mier JW (1993) Antiinflammatory properties of hepatic acute phase proteins: preferential induction of interleukin 1 (IL-1) receptor antagonist over IL-1 beta synthesis by human peripheral blood mononuclear cells. $J$ Exp Med 178:1629-1636.

Wewers MD, Casolaro MA, Sellers SE, Swayze SC, McPhaul KM, Wittes JT, and Crystal RG (1987) Replacement therapy for alpha 1-antitrypsin deficiency associated with emphysema. N Engl J Med 316:1055-1062.

Zhou X, Liu Z, Shapiro L, Yang J, and Burton GF (2015) Low-density lipoprotein receptor-related protein 1 mediates $\alpha 1$-antitrypsin internalization in CD4+ T lymphocytes. J Leukoc Biol 98:1027-1035.

Address correspondence to: Eli C. Lewis, Department of Clinical Biochemistry \& Pharmacology, Faculty of Health Sciences, Ben-Gurion University of the Negev, 1 Rager St., Beer-Sheva 84101, Israel. E-mail: lewis@bgu.ac.il 